\title{
Lack of lipolytic response in infants after endotracheal intubation
}

Claude Marcus, Hans Selldén, Erland Rickardsson, Per-Arne Lönnqvist, Mikael Brönnegård, Peter Arner

\begin{abstract}
The sympathoadrenal response to endotracheal intubation was investigated in nine infants 2-4 months old and in eight adults 2345 years old at the start of inguinal hernia operations. In both infants and adults, heart rate and diastolic blood pressure increased significantly immediately after intubation. In both groups, moreover, there was a mean (SD) reduction in microvascular blood flow in the abdominal skin (infants $-21(14) \%$, adults -14 (7)\%) and in the adipose tissue (infants -7 (4) $\%$, adults $-5(4) \%)$. However, the plasma glycerol concentration did not increase in the infants whereas it increased in the adults by $\mathbf{5 0}$ (12)\%. In conclusion, infants and adults showed similar circulatory reactions during endotracheal intubation but the markedly increased lipolysis rate observed in adults was not seen in the infants. This may indicate that catecholamine induced lipolysis in vivo as well as in vitro is poor during infancy.

(Arch Dis Child 1993; 68: 402-404)
\end{abstract}

Triglycerides stored in the adipose tissue constitute the main energy reserve in man. These lipids may be mobilised from the adipocytes by lipolysis, a process that is regulated by hormones and paracrine substances. In adults, insulin and catecholamines are the only hormones with an acute and pronounced effect on lipolysis. Insulin inhibits lipolysis whereas catecholamines stimulate lipolysis by $\beta$ adrenergic receptors. However, catecholamines that are solely lipolytic in most species also have an inhibitory effect via $\alpha_{2}$ adrenoceptors. ${ }^{12}$

We have shown that in isolated adipocytes obtained from neonates, the lipolytic effect of endogenous catecholamines (adrenaline and noradrenaline) was not significant ${ }^{3}$ and in fat cells from infants, 2-4 months old, it was small because of the enhanced $\alpha_{2}$ adrenoceptor inhibition of lipolysis. ${ }^{+5} \mathrm{~A}$ lower lipolytic effect in vitro of noradrenaline has also recently been reported in prepubertal children. ${ }^{6}$ It is not known whether the catecholamine induced lipolysis is also depressed in vivo, however, or if the reduced effect of catecholamines in vitro during infancy is balanced by a higher blood flow in adipose tissue during infancy.

It is well established that laryngoscopy and endotracheal intubation are associated with an increased sympathoadrenal activity. Increases in blood pressure and heart rate are observed within seconds after starting intubation and in adults, the blood pressure reaches peak levels after 30-60 seconds, caused by an acute catecholamine surge. $^{78}$ Similar circulatory effects during intubation are observed in infants and children. ${ }^{9}$

In the present study we investigated the effects in vivo on both the circulation and the lipid mobilisation of the catecholamine surge caused by endotracheal intubation in infants and adults.

\section{Subjects and methods}

SUBJECTS

Nine infants of 2-4 months old, mean (SD) 12 (5) weeks, and eight adults of 23-45 years old, mean (SD) 27 (8) years, were investigated. All subjects were males who were healthy, of normal weight, and scheduled for inguinal hernia operations. A venous cannula was inserted in the left arm for blood sampling. Adults fasted overnight and infants for four hours before the start of anaesthesia, which was induced by intravenous thiopentone, fentanyl, and pancuronium. Anaesthesia was maintained by a mixture of oxygen $(30 \%)$ and nitrous oxide $(70 \%)$, using controlled ventilation and additional doses of fentanyl and pancuronium. The drugs used have minimal impact on lipolysis according to previous in vitro studies both in infants and adults. ${ }^{+}$ Intravenous fluids were given from the start of anaesthesia and during the investigations. In all patients the fluids were given at a rate of $5 \mathrm{ml} / \mathrm{kg}$ / minute. Five infants were given an isotonic electrolyte-glucose $(2 \cdot 5 \%)$ solution and four infants received isotonic saline. Four adults were given isotonic saline and four were given 5\% glucose. Before oral intubation, the patients were ventilated manually for 5-10 minutes until a circulatory steady state was obtained.

The adults were investigated at Huddinge Hospital and the infants at St Göran's Hospital. The study was approved by the ethics committee of the Karolinska Institute.

\section{MEASUREMENTS OF CIRCULATORY VARIABLES}

Heart rate was recorded by standard electrocardiographic monitoring in the operation ward at each hospital. The blood pressure was measured automatically by a Dinamap (model 1846, Critikon Ltd). The capillary blood flow was measured simultaneously in the adipose tissue and in the dermis by laser Doppler flowmetry (Perimed). The adipose tissue microvascular blood flow was measured with a glass fibre probe, $0.4 \mathrm{~mm}$ diameter, inserted in the subcutaneous adipose tissue at a point between the spina iliaca anterior superior and the umbilicus. The skin probe was placed at a contralateral point. Laser Doppler flowmetry is a well established method for measuring capillary blood flow in various tissues 1 " but it has never 
Table 1 Systolic blood pressure and heart rate in nine infants and eight adults before and 1-2 minutes after endotracheal intubation. Results are mean $(S D)$ except for difference, which is mean $(S E)$

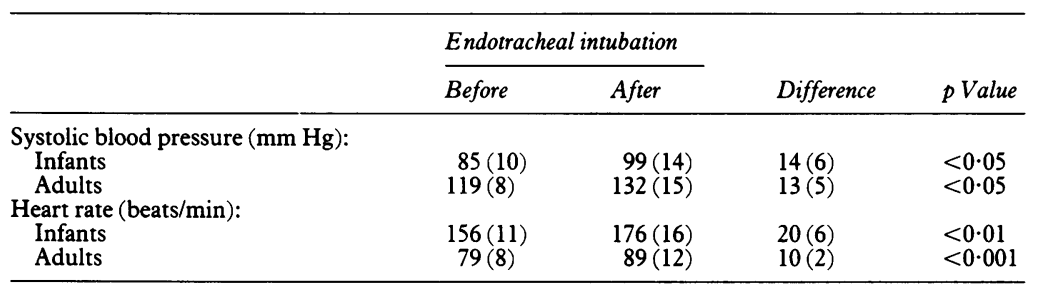

been used for systematic studies in adipose tissue in infants. In all subjects (adults and infants) both in the skin and in the adipose tissue an autonomic variation in blood flow and an artefact from the respiration of the subjects were observed. However, such variations were easily distinguished from those caused by the endotracheal intubation. The glass fibre probe was well tolerated in all but one infant who developed erythema around the probe and an appreciably increased microvascular blood flow. This infant was excluded from the study. In all subjects, skin and rectal temperature were constant during the investigations.

ANALYSES OF METABOLITES AND PLASMA HORMONE CONCENTRATIONS

Blood samples (1 ml with addition of $10 \mathrm{mM}$ EDTA, $20 \mu \mathrm{l}$ ) were obtained 5 minutes before and 10,20 , and 30 minutes after the endotracheal intubation. The samples were taken without venous occlusion and were immediately placed in ice water and thereafter centrifuged. The plasma supernatant was frozen at $-70^{\circ} \mathrm{C}$ until the analyses were performed. The glycerol concentration was analysed by a sensitive kinetic bioluminescence method. ${ }^{12}$ Catecholamines were analysed by high pressure liquid chromatography ${ }^{13}$ and insulin with a commercially available radioimmunoassay method (Pharmacia).

\section{STATISTICAL ANALYSIS}

The Student's paired or unpaired $t$ test or Fisher's least significant difference analysis of variance test were used when appropriate.

\section{Results}

CHANGES IN HEART RATE AND BLOOD PRESSURE Basal (that is, before endotracheal intubation but after induction of anaesthesia) heart rate was higher and blood pressure was lower in the infants than in the adults (table 1). This accorded with well known age dependent changes. Immediately after intubation, heart rate and systolic blood pressure increased significantly in both infants and adults. The increases in blood pressure and heart rate were brief and within 5-10 minutes all patients had the same levels that they had had before intubation.

\section{LASER DOPPLER FLOWMETRY MEASUREMENTS}

All subjects showed a marked reduction in skin capillary blood flow immediately after intubation (fig 1A). However, in the subcutaneous adipose tissue the effects were much milder in both infants and adults (fig 1B) and a significant decrease in adipose tissue capillary blood flow occurred only in the adults.

\section{METABOLIC MEASUREMENTS}

The effects of endotracheal intubation on lipolysis are shown in fig 2 . In the adults a $100 \%$ increase in the basal glycerol concentrations was seen. In the infants basal glycerol concentrations were slightly, but not significantly, higher than in the adults. However, in the infants after intubation no increase in glycerol was seen.

The insulin concentrations were low in both age groups (table 2) and were not affected by saline or glucose infusions.

The catecholamine concentrations determined 10 minutes after endotracheal intubation were slightly higher than those before intubation, but the differences were not significant either in infants or adults (table 2).

\section{Discussion}

In the present study the effects of endotracheal intubation on circulation and lipolysis have been investigated during similar conditions in infants and adults. In adults, marked effects on heart rate, systolic blood pressure, and cutaneous
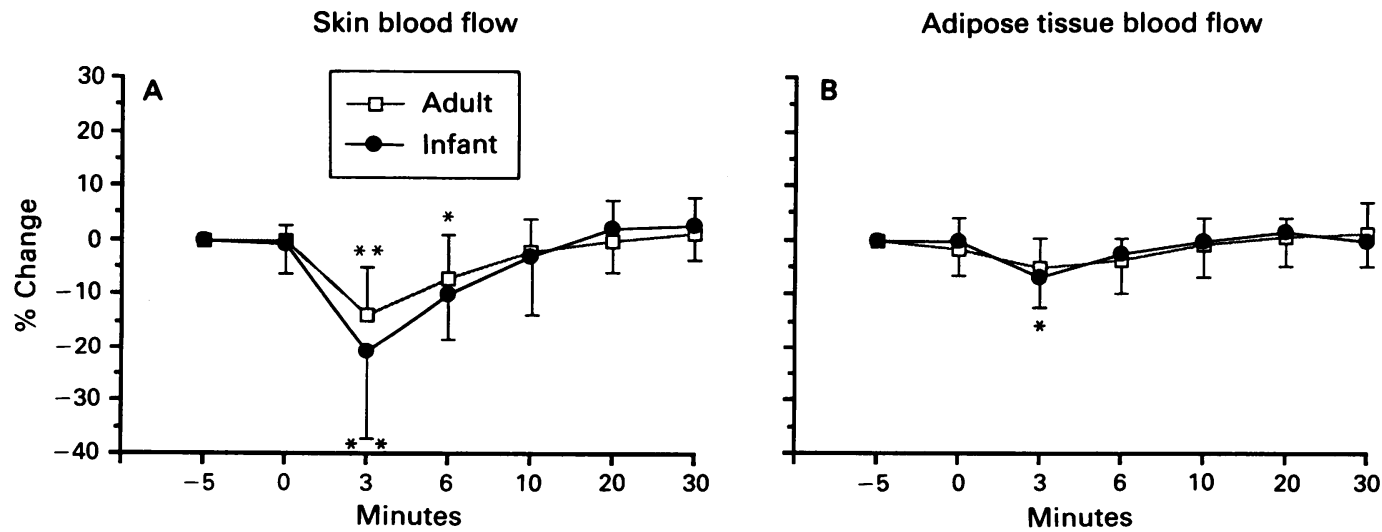

Figure 1 Cutaneous and adipose tissue capillary blood flow during endotracheal intubation. By means of laser Doppler flowmetry measurements the variations in capillary blood flow during intubations were recorded in the abdominal dermis $(A)$ or in the abdominal adipose tissue $(B)$. The scale on the $x$ axis is not linear. Values shown are mean $(S D) ; *=p<0.05$, $* *=p<0 \cdot 01$. 
Table 2 Plasma noradrenaline and insulin concentrations before and after endotracheal intubation in nine infants and eight adults. Results are mean $(S D)$

\begin{tabular}{|c|c|c|c|c|}
\hline & \multicolumn{3}{|c|}{ Noradrenaline $(\mathrm{nmol} / \mathrm{l})$} & \multirow{2}{*}{$\begin{array}{l}\text { Insulin }(U / l) \\
10 \mathrm{~min}\end{array}$} \\
\hline & $-5 \min$ & $10 \mathrm{~min}$ & $20 \mathrm{~min}$ & \\
\hline $\begin{array}{l}\text { Infants } \\
\text { Adults }\end{array}$ & $\begin{array}{l}2.8(0.5) \\
3.4(0.5)\end{array}$ & $\begin{array}{l}3 \cdot 4(0 \cdot 8) \\
4 \cdot 0(0 \cdot 5)\end{array}$ & $\begin{array}{l}3 \cdot 2(0 \cdot 7) \\
3 \cdot 4(0 \cdot 7)\end{array}$ & $\begin{array}{l}5 \cdot 5(0 \cdot 4) \\
7 \cdot 7(1 \cdot 1)\end{array}$ \\
\hline
\end{tabular}

blood flow were found indicative of increased sympathoadrenergic activity. Such effects have been documented previously. ${ }^{78}$ In adults a significant increase in lipolysis rate, as mirrored by an enhanced plasma glycerol concentration, was also found. As catecholamines are the only lipolytic hormones in adults it may be inferred that the enhanced glycerol concentration, which was found after intubation, was also induced by a catecholamine surge induced by the intubation.

In the infants similar effects of laryngoscopy and intubation were seen as regards all circulatory parameters, although the decrease in adipose tissue blood flow in infants was not significant. However, the variations in capillary blood flow detected with laser Doppler flowmetry were expressed as a percent of the basal flow. Although the biological zero level is probably higher than the instrumental zero level ${ }^{14}$ we used the instrumental zero because we were unable to define accurately the biological zero level. Thus the variations in capillary circulation presented in this study are probably underestimated.

Unlike in the adults, no increased lipolysis rate was observed in the infants. This may indicate that the increased sympathoadrenal activity during the intubation procedure, which caused marked effects on the circulation, had no effect on lipolysis in infants. Slightly but not significantly higher catecholamine concentrations were found in both infants and adults 10 minutes after the intubation. The protocol was designed primarily to study variations in lipolysis and it has been shown that noradrenaline concentrations in plasma are almost normalised 10 minutes after intubation."

Insulin is a potent antilipolytic hormone. In theory, infusions of low concentrations of glucose may induce an increased release of insulin which, in turn, may depress the rate of lipolysis. However, the insulin plasma concentration was low in all subjects investigated, both infants and adults. Furthermore, the insulin concentrations during glucose infusions were compared with the insulin concentrations when saline alone was given and no difference was observed in either infants or adults.

It is previously shown during in vitro conditions that catecholamines have a weak lipolytic effect in fat cells from neonates, infants, and children due to an enhanced antilipolytic $\alpha_{2}$ effect. ${ }^{+615}$ It has also been previously observed that there is no correlation between the circulating concentrations of catecholamines and lipolytic products during delivery ${ }^{16}$ and the first hours of life. ${ }^{17}$ The lack of lipolytic response in infants after endotracheal intubation found in the present study further supports previous

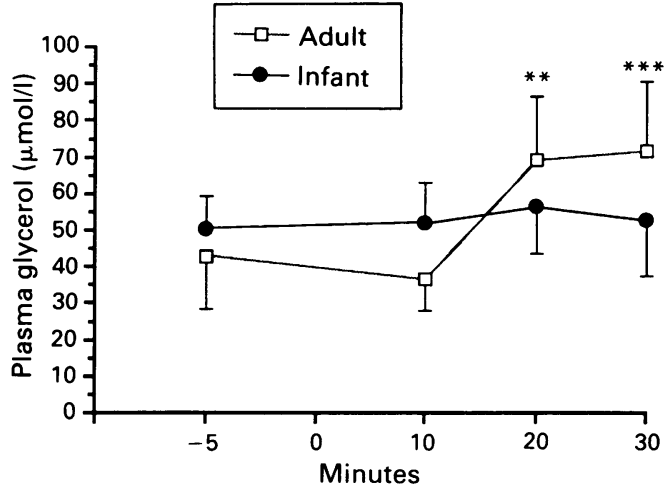

Figure 2 Lipolysis during endotracheal intubation. Venous plasma glycerol concentrations were measured before and after endotracheal intubations at indicated times. The scale on the $x$ axis is not linear. Values shown are mean $(S D)$; $* *=p<0 \cdot 01, * * *=p<0 \cdot 001$.

findings that catecholamines have an impaired lipolytic effect during infancy. We thank Associate Professor Paul Hiemdahl for his invalu-
able advice at the beginning of this study and Professor Hugo Lagercrantz for the generous help with analyses of Hugo Lagercra

This study was supported by grants from the Swedish Society of This study was supported by grants from the Swedish Society of Medicine, the Swedish Medical Research Council (19X-9941, 19X-01034, 19k-07184), Karolinska Institute, the Golje
Memorial, The Crown Princess Lovisa/Thileman, the Swedish Memorial, The Crown Princess Lovisa/Thileman, the Swedish
Diabetes, the General Maternity Hospital, the Nordic Insulin, Harald and Greta Jeansson, Magnus Bergwall and Eriksson Research Foundations.

1 Garcia-Saintz J, Fain J. Adrenergic regulation of adipocyte metabolism. F Lipid Res 1983; 24: 945-66.

2 Levitzki A. Receptor to effector coupling in the receptor dependent adenylate cyclase system. $\mathcal{F}$ Recept Res 1984; 4 399-409.

3 Marcus C, Ehren H, Bolme P, Arner P. Regulation of lipolysi during the neonatal period: importance of thyrotropin f Clin Invest 1988; 82: 1793-7.

4 Marcus C, Karpe B, Bolme P, Sonnenfeld T, Arner P Changes in catecholamine-induced lipolysis in isolated human fat cells during the first year of life. $\mathcal{F}$ Clin Inzest 1987; 79: 1812-8.

5 Marcus C, Sonnenfeld T, Karpe B, Bolme P, Arner P. Inhibition of lipolysis by agents acting via adenylate cyclase in fat cells from infants and adults. Pediatr Res 1989; 26: in fat cells

6 Rosenbaum M, Presto E, Hirsch J, Leibel R. Regional differences in adrenoceptor status of adipose tissue in adults and prepubertal children. $\mathcal{F}$ Clin Endocrinol Metab 1991; 73

7 Russel WJ, Morris RG, Frewin DB, Drew SE. Changes in plasma catecholamine concentration during endotrachea intubation. Brf Anaesth 1981; 53: 837-9.

8 Low JM, Harvey JT, Prys-Roberts C, Dagnino J. Studies of anaesthesia in relation to hypertension. Br $\mathcal{F}$ Anaesth 1986 58: 471-7.

9 Tibballs J, Malbezin S. Cardiovascular responses to induction of anaesthesia with thiopentone and suxamethonium in infants and children. Anaesth Intensive Care 1988; 16: 278 84.

10 Swetnam TM, Aarnoudse JG, Ziljstra WG. Red blood cell flow in the fetal scalp during hypoxemia in the chronic sheep 20: $407-10$.

11 Strömberg B, Öberg PÅ, Sedin G. Transepidermal water loss in newborn infants. Acta Paediatr Scand 1983; 72: 735-9.

12 Biörkhem I, Arner P, Thore A, Östman J. Sensitive kinetic bioluminescent assay of glycerol release from human fat cells. F Lipid Res 1981; 22: 1143-7.

13 Hjemdahl P, Daleskog M, Kahan T. Determination of plasma catecholamines by high performance liquid chromatography with electrochemical detection: comparison with a radioenzymatic method. Life Sci 1979; 25: 131-8.

14 Caspary L, Creutzig A, Alexander K. Biological zero in laserDoppler fluxmetry. Int $\mathcal{F}$ Microcirc Clin Exp 1988; 7: $367-$ 71 .

15 Arner P, Marcus C, Karpe B, Sonnenfeld T, Bolme P. Role of alpha-adrenoceptors for adipocyte size in man. Eur $\mathcal{F}$ Clin Invest 1987; 17: 58-62.

16 Hägnevik K, Faxelius G, Irestedt L, Lagercrant\% H, Lundel $B$, Persson B. Catecholamine surge and neonatal adaptation in the newborn after vaginal delivery and caesarean section Acta Paediatr Scand 1984; 73: 602-9.

17 Hertel J, Kuhl C, Christensen NJ, Pedersen SA. Plasma noradrenaline and adrenaline in newborn infants of diabetic mothers: relation to plasma lipids. Acta Paediatr Scand 1985; 74: $521-4$ 